\title{
Los niños y la familia: entre el imaginario y la separación*
}

\section{Children and the family: between the imaginary and separation}

\author{
Manuela Medina Gómez ${ }^{\circledR}$, Daniela Giraldo Marín ${ }^{\circledR}$, Nataly Posada Castaño ${ }^{3}$
}

Para citar este artículo: Medina, M., Giraldo, D., Posada,

Recibido: 12-08-2019 - Aceptado: 14-06-2020

N. (2020). Los niños y la familia: entre el imaginario y la

separación. Infancias Imágenes, 19(2), 109-123

\section{Resumen}

Este artículo es resultado de una investigación que se centró en los imaginarios de familia que construyen los niños antes y después de la separación de los padres. La metodología correspondió a un paradigma cualitativo, bajo un enfoque hermenéutico, privilegiando la narrativa como estrategia. La población estuvo compuesta por seis niños del grado tercero y sus respectivas madres. Los resultados indican que el imaginario de familia se transforma después de la separación y que los cambios en la dinámica familiar inciden en este. Se concluye que después de la ruptura de los padres los miembros de la familia buscan establecer vínculos con otras personas, familiares, amigos o grupos sociales como la escuela; de esta última los padres, de modo particular, esperan recibir apoyo para reducir el impacto emocional de la separación en la vida de los niños.

Palabras clave: desintegración familiar, familia, infancia, papel de la familia, parentesco.

\section{Abstract}

This article, as result of a research, includes the imaginaries of family that children build, before and after the separation of parents. The Methodology responded to a qualitative paradigm, under a hermeneutic approach, privileging narrative as a strategy. The population was composed of six children from third grade and their respective mothers. The results indicate that the family imaginary is transformed after the separation and that the changes that affect family dynamics affect this. It is concluded that after parents' rupture, all the family members start looking for bonds with other people, family, friends or social groups to face the difficulties that this change supposes; and parents expect support from the school to reduce the impact of separation on children's lives.

Keywords: childhood, family, family disintegration, family role, kinship.

* Artículo derivado de la investigación titulada "Resignificar el concepto de familia desde el sentir y el imaginar del niño", avalada por la Universidad Católica Luis Amigó, realizado entre agosto de 2017 y mayo de 2018, sin financiación.

1 Licenciada en Educación Preescolar, Universidad Católica Luis Amigó. Docente del colegio de la Compañía de María - La Enseñanza (Medellín). Correo electrónico: manuelamedinago@gmail.com. Orcid: https://orcid.org/0000-0003-3672-6439

2 Licenciada en Educación Preescolar, Universidad Católica Luis Amigó. Docente del liceo Francisco Restrepo Molina. Correo electrónico: dany3849@gmail.com. Orcid: https://orcid.org/0000-0003-1229-7924

3 Licenciada en Educación Preescolar, Universidad Católica Luis Amigó. Docente AIN-Comfenalco Antioquia. Correo electrónico: natalyposadacasta@gmail.com. Orcid: https://orcid.org/0000-0002-9248-7498 


\section{Introducción}

La familia como primer agente socializador de los niños ${ }^{1}$ es el grupo ideal para establecer vínculos que facilitan el desarrollo de su dimensión socio-afectiva y les prepara para enfrentar el mundo con autonomía y seguridad. En la actualidad la cifra de divorcios ha aumentado ${ }^{2}$, por lo que los niños que han vivido la separación de los padres tal vez han transformado su imaginario de familia. Cuando los niños hablan acerca de esta o realizan representaciones de la misma construyen imaginarios en los que se vislumbran los vínculos que teje con las personas que considera su familia. Dentro del contexto escolar, estos imaginarios de familia son contrastados con los de otros estudiantes, sobre todo en actividades que involucran a la familia. Este tipo de comparaciones suelen agudizar el dolor que causa la separación de los padres en los niños.

Teniendo en cuenta las consideraciones anteriores, se decidió hacer un rastreo de antecedentes para identificar estudios en los que se relacionara 110 la familia y la separación de los padres desde la perspectiva de los niños. En este se identificaron estudios que, aunque no abordan de manera puntual la relación propuesta, sí abordan el tema de la separación de los padres y las implicaciones que tiene el divorcio en el ámbito afectivo, sentimental y conductual de los niños. Asunto que, sin duda, ofrece algunas luces para pensar el imaginario de familia que construyen los niños después de la separación de sus padres.

Entre los referentes más relevantes se destaca el estudio de Cifuentes y Milicic (2012), en el que se evidencia "la experiencia de niños chilenos respecto a la separación de sus padres y el significado que dicha experiencia tiene actualmente en sus vidas" (p. 469). Este mismo estudio concluye que la segunda infancia aprecia la separación como una experiencia negativa en sus vidas. Sin embargo, la descripción de los hechos no se queda en el dolor y el sufrimiento, sino que, por el contrario, se pueden

1 En este texto se emplea el término niños, teniendo en cuenta la disposición de la RAE que afirma "El uso genérico del masculino se basa en su condición de término no marcado en la oposición masculino/femenino". Se aclara que este incluye a las niñas.

2 De acuerdo con un artículo publicado por la revista Dinero el 20 de abril de 2017, el incremento de los divorcios en Colombia es del $39 \%$ anual entre el año 2014 al 2016. En Antioquia por cada tres matrimonios hay un divorcio. identificar y describir los procesos de avance y superación de la crisis.

Por su parte, Muñoz-Ortega et al. (2009) analizaron los sentimientos y pensamientos que se presentan en los niños a raíz de la separación de los padres y la evolución de los mismos a través del tiempo. Allí también se afirma que la relación de pareja es uno de los factores más importantes para el desarrollo del niño. E insisten los autores en que el clima emocional necesita de la cooperación de ambos padres y que los conflictos o crisis de pareja que no se superan imponen a los hijos una carga emocional y una serie de pensamientos y sentimientos de sí mismo y de los demás que pueden tener consecuencias a nivel relacional.

Correa et al. (2016) en su investigación, la cual pretendió describir las representaciones e imaginarios de familia y su relación con la dimensión socio afectiva que han construido los niños del grado párvulos, señalan que cada niño es un ser único que debe ser visto desde su singularidad para poder comprender su comportamiento, al igual que mejorar la relación con sus pares. Este estudio resalta el papel de la familia como pilar fundamental para fortalecer el desarrollo de la dimensión socio-afectiva, así como la importancia del apego y de las dinámicas familiares en el desarrollo.

Los estudios mencionados, y otros que irán apareciendo en este artículo, son fundamentales para el objetivo que se propone desarrollar, a saber: comprender los imaginarios de familia que construyen los niños antes y después de la separación de sus padres.

El desarrollo del estudio abordó las siguientes categorías: familia, dinámica familiar e imaginario. Para la categoría de familia se tomó como referente a Domínguez (2007) quien expresa que esta "tiene lugar en la socialización primaria, en la que aprendemos la propia identidad, la primera y más radical" (p. 20). Para dinámica familiar se retoma lo expuesto por Uribe (2012) y Gallego (2012), quienes indican que la familia como organización social es histórica y se ve afectada por las transformaciones estructurales de la sociedad; de igual forma, ella construye sus propias dinámicas internas. De ahí que para comprenderla hay que tener en cuenta sus características: comunicación, funciones, afecto, autoridad y tiempo libre. Por su 
parte, para el imaginario este estudio se acoge a lo mencionado por Escobar (2000) y Turrent y Villaseñor (2009), quienes afirman que el imaginario es un conjunto de imágenes mentales, un resultado de elementos que se relacionan de forma recíproca y pueden formar una estructura, un sistema real, en la medida en que actúan los comportamientos y las sensibilidades; estas ayudan al sujeto a ordenar la realidad y otorgan características a un referente.

Finalmente, este estudio resulta relevante en la medida en que brinda elementos para comprender la percepción de los niños acerca de la familia y de la separación de los padres, a la par que aporta elementos que ayudan a la familia y a la escuela a afrontar una situación tan compleja y recurrente en el contexto actual.

\section{Metodología}

El enfoque con el que se desarrolló la investigación es cualitativo y el método hermenéutico. Con esto se procuró hacer una aproximación global de una situación social para explorarla, describirla y comprenderla (Bonilla, citado en Bonilla y Rodríguez, 1995). Esto, en el caso concreto de la investigación, con el propósito de comprender los imaginarios de familia que construyen los niños del grado tercero de la institución educativa Lola González (IELG), antes y después de la separación de sus padres. La estrategia que privilegió este proyecto fue la narrativa, sustentada en Bruner (1988), quien señala que esta es una forma de construir realidad.

Las técnicas que se emplearon para la recolección de información fueron la entrevista y el taller interactivo. Para el análisis de la información se desarrollaron matrices categoriales; del mismo modo, se tematizó y trianguló la información recolectada de acuerdo con las categorías. Las consideraciones éticas que contempló el estudio conllevaron la firma del consentimiento informado como evidencia de la participación voluntaria en el desarrollo de la investigación y se garantizó a los participantes la completa reserva de la identidad.

\section{Participantes}

Formaron parte del estudio seis niños del grado tercero de primaria de la IELG, ubicada en el barrio Santa Lucía de la comuna 12 de Medellín,
Colombia. La muestra estuvo compuesta también por el acudiente de cada uno de los niños, papel que en todos los casos y de modo particular es desempeñado por la madre. El total de la muestra fue de 12 personas: seis niños y seis adultos.

Los criterios para la selección de la muestra fueron los siguientes: 1) ser estudiante del grado tercero de la IELG, con edad comprendida entre los 8 y los 9 años de edad; 2) ser hijo de padres separados cuya separación se hubiera dado en un periodo de tiempo no inferior a tres meses y cuya convivencia se hubiera dado bajo el mismo techo; 3) el deseo de participar de manera voluntaria en la investigación manifestado a través de la firma del consentimiento informado.

\section{Herramientas}

Se llevaron a cabo dos entrevistas semiestructuradas, una a las seis madres y la otra a los seis niños, con el fin de "conocer la perspectiva y el marco de referencia a partir del cual las personas organizan su entorno y orientan su comportamiento" (Patton citado en Bonilla, 1995, p. 93). A continuación, se describe el propósito de cada una de las entrevistas:

- La entrevista a las madres tenía el propósito de conocer los imaginarios de familia que construyen los niños participantes del estudio a través de la percepción de sus madres y su relación con las características de la dinámica familiar.

- La entrevista a los niños tenía como objetivo identificar los imaginarios de familia que construyen los niños participantes del estudio antes y después de la separación de sus padres y su relación con las características de la dinámica familiar.

Asimismo, se realizaron cinco talleres interactivos con los niños con la intención de "visibilizar sentimientos, vivencias y formas de ser, creer, pensar, actuar, sentir y relacionar" de los sujetos (García et al., 2002, p. 71). Los talleres realizados y su propósito se enuncian a continuación:

- El taller n. ${ }^{1}$, Mi familia es así: identificar situaciones, espacios y personas que representan lo que sucede en la vida de los niños 
participantes del estudio antes y después de la separación de los padres.

- El taller n. ${ }^{\circ}$, Puedo ser...: identificar por medio de representaciones dramáticas las características de la dinámica familiar antes y después de la separación.

- El taller n. ${ }^{\circ} 3$, Mi cuerpo-mi familia: determinar la identidad y las estéticas corporales de los participantes del estudio antes y el después de la separación de los padres, a partir de lo simbólico y lo imaginario.

- El taller n. ${ }^{\circ}$ 4, Cuenta cuento: comprender los imaginarios de familia que construyen los niños hijos de padres separados.

- El taller n. 5, Así veo, tú qué ves: identificar la incidencia de los imaginarios de familia de los niños con padres separados en las características de la dinámica familiar.

La información recolectada en cada uno de los talleres se registró en diarios de campo, pues esto, según Porlán y Martín (2000), constituye una fuente importante de información para el investigador; además, permite monitorear la observación, así como organizar, analizar e interpretar los datos recolectados.

\section{Procedimiento}

Para la ejecución del proyecto se seleccionaron los tres grupos del grado tercero de la IELG, se identificaron los niños hijos de padres separados y se procedió a citar a las familias a una reunión informativa. En total se convocaron 20 familias de las cuales se presentaron únicamente nueve madres. De las nueve madres asistentes ocho manifestaron su deseo de hacer parte del estudio. Sin embrago, una de ellas no cumplía con los criterios definidos para la selección de la muestra, pues nunca convivió con el padre del niño bajo el mismo techo. La investigación inició con una muestra de 14 personas, siete niños con sus respectivas madres, no obstante, una vez iniciado el estudio una de las madres manifestó su deseo de abandonar el estudio argumentando problemas de salud, quedando una muestra final compuesta por 12 participantes.

Para la recolección de la información se programaron seis reuniones de 20 minutos con las madres y 11 encuentros de entre 20 y 45 minutos con los niños. El propósito de las reuniones era la realización de las entrevistas, con cada uno de los participantes, y de los talleres.

Para el análisis de la información recolectada en cada una de las reuniones se desarrolló una matriz categorial en la que se sistematizó la información y se codificaron los participantes. Para las madres se utilizó un número entero (1, 2, 3, etc.), para los hijos un número decimal conformado por el entero de la madre y el número uno; en efecto, si el identificador de la madre es 1 (entero), el código del hijo es 1.1 (decimal), si el identificador de la madre es 2, el código del hijo es 2.1. Luego, se tematizó y trianguló la información recolectada de acuerdo con las categorías familia, dinámica familiar e imaginario.

El proceso de triangulación se desarrolló a través de la matriz categorial. En ella se registraron los testimonios de todos los participantes (madres e hijos), con su respectivo código, en relación con las categorías del estudio y los enunciados de referencia. Cada una de estas relaciones dio lugar a una sección de cometarios en la que los investigadores consignaron sus apreciaciones estableciendo una articulación entre los testimonios de los participantes y la literatura consultada.

\section{Discusión y resultados}

A continuación, se presentan los resultados y la discusión, atendiendo a los objetivos específicos: 1) identificar los imaginarios de familia que poseen los niños participantes del estudio antes y después de la separación de los padres y 2) reconocer la incidencia de las características de la dinámica familiar en los imaginarios de familia que construyen los niños. Es válido mencionar que se hace énfasis en el antes y el después de la separación de los padres y que los resultados presentados hacen alusión a los niños, aclarando que se trae a colación los testimonios de las madres para contrastar la información de los hijos.

El imaginario de familia como grupo de apoyo Para Lacan, la familia: 
aparece como un grupo natural de individuos unidos por una doble relación biológica: la generación, que da lugar a los miembros del grupo; las condiciones de ambiente que postula el desarrollo de los jóvenes y que mantienen al grupo, siempre que los adultos progenitores cumplan la función. (1977, p. 47)

Como él lo expresa, los adultos progenitores son quienes mantienen al grupo unido. Cuando estos deciden separarse se presenta una ruptura en las relaciones y en las funciones que cada uno cumple dentro del hogar. Este hecho hace que el imaginario de familia de los niños se transforme y se divida en un antes (relacionado a la felicidad) y un después (vinculado a la tristeza). Como lo expresan Cifuentes y Milicic, la separación de los padres es "un hecho que genera un quiebre en la noción que el niño tiene de su realidad familiar exponiéndolo al estrés de tener que enfrentar cambios significativos en sus rutinas de vida" (2012, p. 471). Cabe resaltar que pasado algún tiempo de este suceso los niños crean redes de apoyo o vínculos con otras personas, diferentes a los padres, que les permiten reconfigurar la familia.

Para efectos de este trabajo, entenderemos la familia como un grupo social en el que las personas se entrelazan por vínculos biológicos o filiales y que, a través de la interacción, busca la consecución de unos proyectos más o menos determinados. Por otro lado, el imaginario de familia es considerado como la forma en que las personas construyen esquemas (representaciones mentales) que les permiten percibir la realidad de la familia y del contexto familiar.

En este sentido, la familia es vista por los niños participantes del estudio como un grupo de personas que se apoyan, se quieren y se cuidan. Esta visión está ligada a su experiencia en el seno de la familia y se vincula a los relatos de las madres. Silvana ${ }^{3}$, una de las niñas participantes, definió a la familia como las personas que la cuidan y la quieren; su madre expresó:

La familia es un grupo de personas que se apoyan mutuamente en todos los aspectos como el emocional,

3 Por cuestiones de privacidad de los participantes los nombres aquí mencionados son ficticios. el sentimental, el económico; es una unidad donde cada quien debe contar con el otro. (Participante 2)

Jerónimo, otro niño participante, dijo:

La familia para mí son las personas que me ayudan a crecer, a vivir y me ayudan a salir adelante, la familia para mi es importante. (Participante 1.1)

Este es el caso de otra madre, Lorena, quien comentó que la familia:

Es un grupo de personas que se ayudan mutuamente a salir adelante y tener propósitos. (Participante 6)

Luego, al preguntarle a ella por las actividades que realizaban en familia antes de separarse, expresó:

Nosotros nunca vivimos así. (Participante 6)

Esto lo hace porque el imaginario de familia que ella ha construido también está en relación con el apoyo que se brindan los miembros de una familia, a los propósitos y proyectos en común, y este tipo de apoyo nunca lo ha tenido por parte del padre. Por esta razón, la participante 6 manifestó que la abuela paterna de la niña es el remplazo de él, pues vive muy pendiente de ella.

\section{La unión evoca felicidad}

En los diferentes talleres los niños participantes dibujaron a su familia, antes de la separación, la representaron feliz y unida; en algunos casos resaltaban ese sentir escribiendo la palabra feliz al lado del dibujo o asignándola a modo de título. Paulina dibujó la suya tal como lo expresó su madre antes de que ella lo hiciera, los plasmó a todos juntos y felices tomados de las manos; a diferencia de Paola (participante 3.1) y Marcela (participante 4.1), la primera pintó a su familia feliz pero no incluyó a su padre, a pesar de que expresa que los niños que tienen a sus padres unidos:

Deben de estar muy felices y aprovechar mientras los tienen juntos, porque uno no sabe en qué momento se pueden ir. (Participante 3.1) 
Y la participante 4.1 dibujó únicamente a sus padres felices y escribió:

Mi papá y mi mamá eran felices, se amaban.

Puesto que la ruptura se dio entre los padres, el vínculo entre estos y sus hijos permaneció. En el relato de la entrevista, Marcela cuenta que todos los fines de semana se van a dormir donde el papá:

Mi papá nos lleva a la casa de él, nos pone a ver películas en el celular, porque él no tiene televisor. Donde él vive no es una casa, es una pieza, y para poder dormir allí mi papá nos compró una colchoneta chiquita muy cómoda, él mismo la hizo. (Participante 4.1)

A continuación, se muestran los dibujos realizados por los niños participantes del estudio ${ }^{4}$ y se aclara que "la mayoría de los dibujos que los niños hacen acerca de su familia, no representan a la familia real y objetiva, sino que se producen altera114 ciones [...], a través de las cuales se manifiestan los sentimientos del sujeto" (Corman, 1967, p. 53). En estos se pueden identificar esos imaginarios de familia que construyen los niños antes de la separación de los padres.

Los niños que han pasado por la separación de los padres consideran que el tenerlos unidos representa algo bueno ${ }^{5}$ para ellos porque pueden compartir más tiempo juntos. Esto es debido a que, en la mayoría de los casos, cuando los padres se separan tienden a distanciarse de sus hijos.

En algunas ocasiones los niños hijos de padres separados, a pesar de haber vivido situaciones traumáticas con respecto a la separación, anhelan volver a convivir con sus padres. Como en el caso de Silvana, ella en su discurso expresó que ver a sus padres felices la hace sentir bien, porque puede compartir con los dos:

Me hace feliz, porque los veo a ellos dos felices y me hacen sentir a mi feliz, porque puedo compartir con los dos. (Participante 2.1)

4 Las imágenes que se exponen en este artículo tienen el propósito de mostrar la forma como los niños perciben y recrean a la familia antes y después de la separación, sin ahondar en una profunda interpretación de los dibujos y sus trazos.

5 Expresión utilizada por los niños participantes del estudio.
Y dice que es bueno estar juntos porque después de la separación sus padres se distanciaron. Con base en lo anterior, se pude afirmar que el imaginario de familia antes de la separación corresponde con el sentimiento de felicidad.

\section{La separación como sinónimo de tristeza}

Después de la separación de los padres la familia se transforma, la unidad entre los miembros se diluye y los niños empiezan a expresar sentimientos de tristeza con respecto a este suceso. En relación con lo anterior, Cifuentes y Milicic plantean que:

La separación de los padres ha sido descrita por algunos autores como una de las experiencias más difíciles y dolorosa de enfrentar para los hijos. La familia constituye el soporte psicológico, físico y emocional del niño hacia la madurez. Con la separación de los padres, la estructura familiar previa se modifica provocando en los niños sentimientos de soledad y temor respecto de lo que ocurrirá en su cotidianidad y en el futuro. (2012, p. 470)

En las representaciones gráficas que los niños realizaron de su familia después de la separación se identifican ciertos cambios que ellos consideran sufre la familia. En los dibujos aparece una línea que divide a sus integrantes, el padre queda a un lado, la madre y los hijos al otro, ambos con lágrimas en sus rostros. En algunos casos aparece la palabra tristeza acompañando el dibujo. Paola plasmó a la familia triste; sin embargo, omite de nuevo a su padre. Tatiana, la madre, manifiesta que Paola:

Cuando realiza dibujos hace a mi mamá, a la hermana, ella y yo. Ella nunca hace al papá. (Participante 3)

Algunas madres consideran que la separación no implica un cambio relevante en la concepción de familia de los niños cuando esta se dio a temprana edad, afirmando que no convivieron mucho con su padre. Este es el caso de Paulina, quien expresó que después de la separación de sus padres se siente triste; contrario a lo que relata su madre, quien dice que ella no cambió mucho la forma de ver o pensar la familia: 


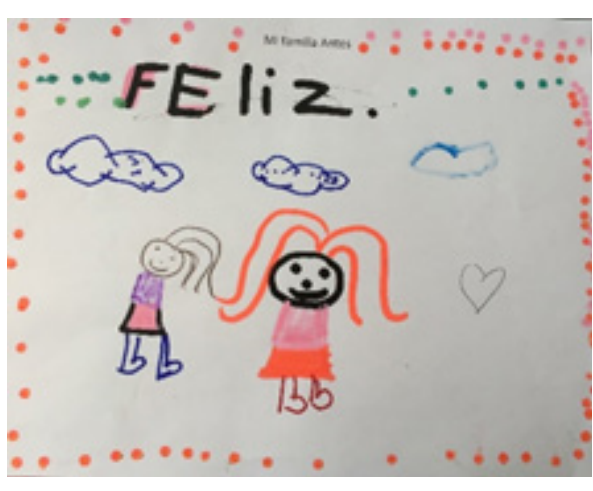

Figura 1. Participante 3.1

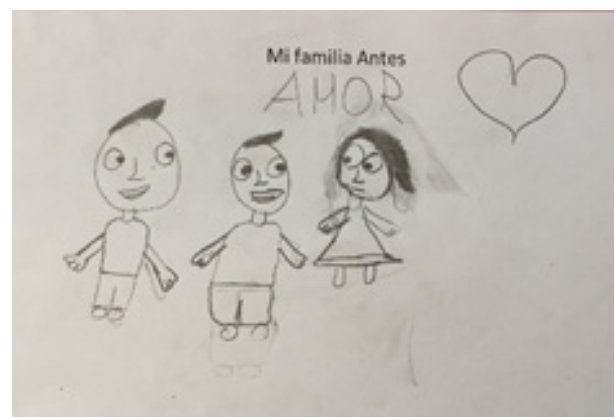

Figura 3. Participante 1.1.

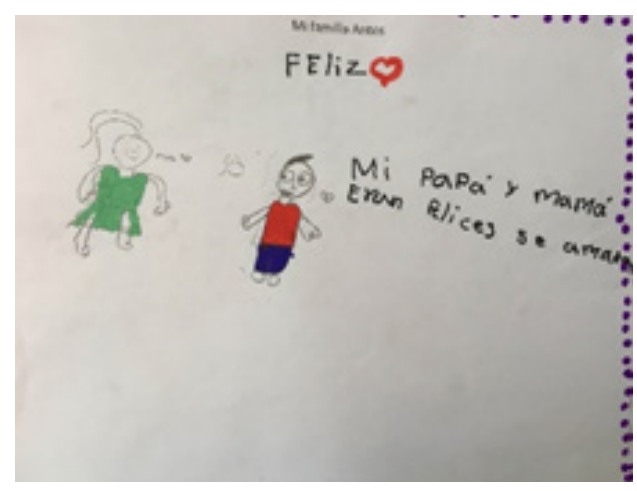

Figura 2. Participante 4.1.

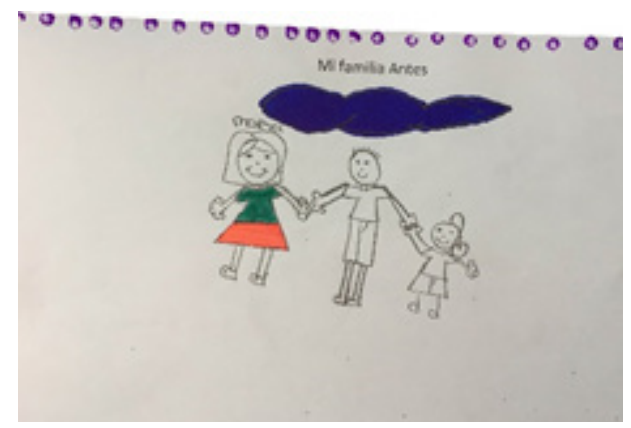

Figura 4. Participante 6.1

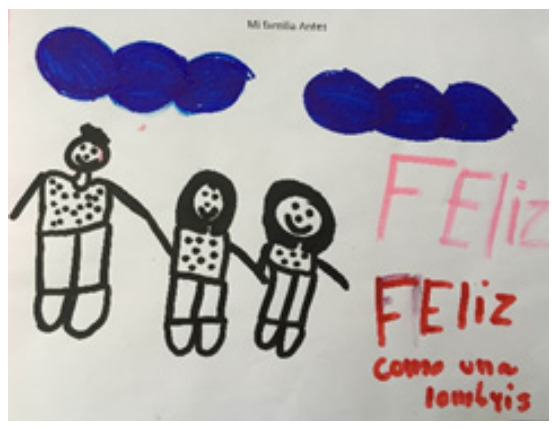

Figura 5. Participante 2.1.

Porque ella no estaba tan acostumbrada a estar con el papá. (Participante 6)

Al respecto Wallerstein y Blakeslee (citados en Cifuentes y Milicic, 2012) manifiestan que en la separación:

lo que resulta bueno para los adultos no necesariamente es favorable para los niños. Los niños poseen sus propias creencias, sentimientos e ideas respecto de la separación de sus padres. Así, las circunstancias que enriquecen la vida del adulto luego de la separación, impone cambios y pérdidas significativas que los niños deben enfrentar. De ahí que la separación interfiera de modo temporal o permanente en los procesos evolutivos de los niños. (p. 470)

Es por esto por lo que aún después de algunos años de estar separados, Paulina afirmó:

En el proceso de separación yo me sentía mal porque cada que miraba la foto de mi papá me ponía a llorar y todavía lloro. (Participante 6.1)

Sin embargo, la madre cree que la separación no ha afectado a su hija por el hecho de haber 


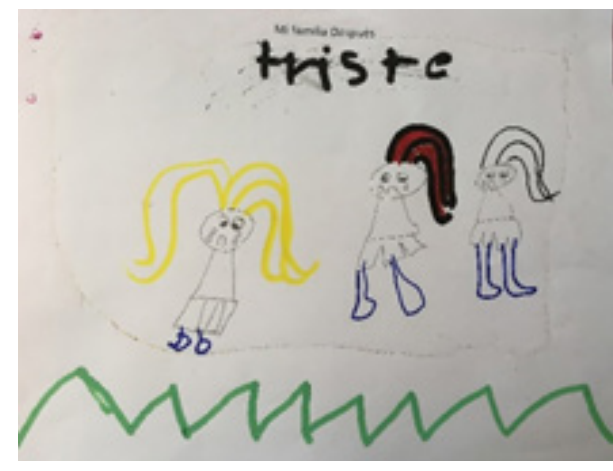

Figura 6. Participante 3.1.

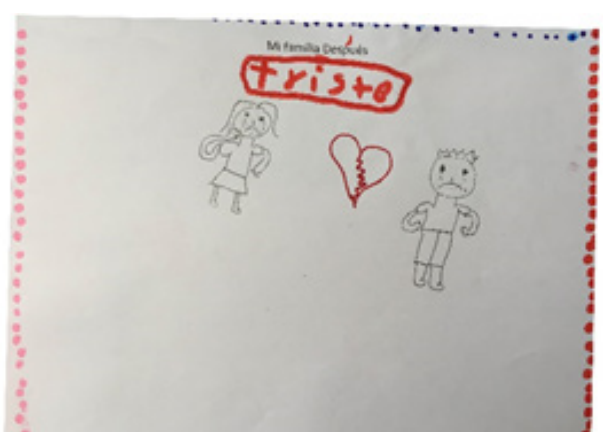

Figura 8. Participante 4.1.

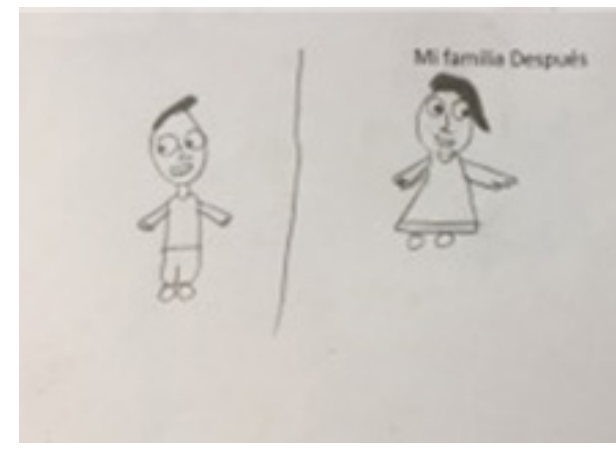

Figura 7. Participante 1.1.

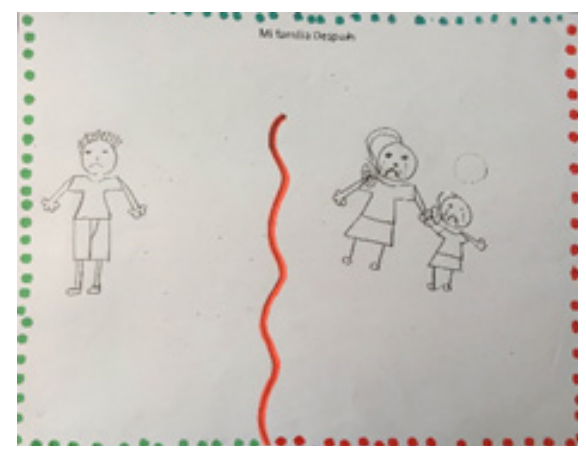

Figura 9. Participante 6.1.

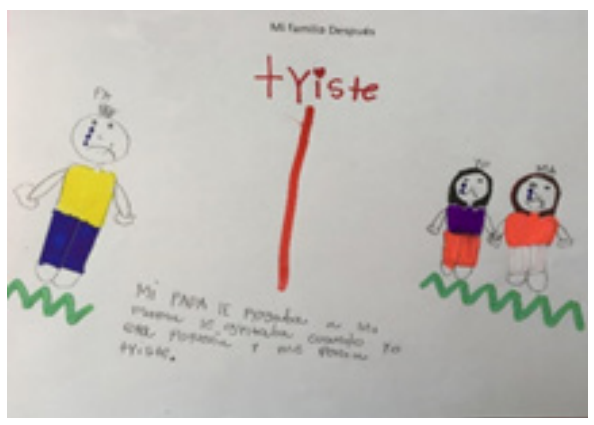

Figura 10. Participante 2.1.

compartido poco tiempo con su padre y, como lo expresaron antes Wallerstein y Blakeslee, el que para los padres resulte bueno perder comunicación entre ellos porque no se entienden, para los hijos este hecho significa una pérdida más que deben enfrentar. De ahí que el Ilanto que expresa la participante 6.1 en el testimonio y las lágrimas que dibujan los demás participantes sea una manifestación de pérdida y tristeza.

Jerónimo relató que a pesar de que cree que tiene una buena vida la tiene a medias. A veces llora porque sus padres se separaron, a él le gustaba antes cuando estaban juntos. Al respecto, cuando se le preguntó qué piensa acerca de las familias que tienen a sus padres juntos, expresó:

que son muy afortunados porque no se le han separado y tienen una buena vida. Yo creo que tengo una buena vida, pero a medias, porque a veces lloro porque se separaron, a mí me gustaba antes, cuando estaban juntos. (Participante 1.1)

Además, al hablar acerca de cómo se siente después de la separación, menciona que 
medio medio, no me hace falta nada, pero me deprimo, me pone triste que mi papá y mi mamá se hayan separado. (Participante 1.1)

Es válido reiterar que el imaginario de familia que construyen los niños se transforma, y después de la separación se vincula a la tristeza. Las imágenes que se presentaron fueron desarrolladas en el taller n. ${ }^{\circ} 1$ llamado Mi familia es así, y en relación con el apartado anterior, en el que se presentaron los dibujos de la familia antes de la separación, sirven como garante para confirmar la transformación que sufre la familia para los niños después de la separación de los padres.

\section{Las características de la dinámica} familiar en el imaginario de familia Cuando los padres se separan los papeles, la autoridad, el afecto, la comunicación y el tiempo libre se transforman, pues varían las dinámicas que hasta entonces se habían establecido en el hogar. Estos cambios inciden en el imaginario de familia que construyen los niños. "La dinámica familiar tiene principalmente siete dimensiones: los roles, la autoridad, las normas, los límites, las relaciones afectivas, la comunicación y el uso del tiempo libre" (Viveros y Arias, citados en Viveros, 2010, p. 396).

A continuación, se mencionan algunas de las características de la dinámica familiar. Se resaltan las que más mencionan los participantes del estudio e influyen en el imaginario de familia que configura el niño después de la separación de los padres.

\section{Funciones y autoridad}

Para Páez, las funciones se establecen en la familia a partir de la interacción entre los miembros como individuos sociales (1984, p. 25). De acuerdo con Gutiérrez, "El conflicto de roles se agudiza en las familias incompletas, sea cabeza económica femenina o masculina, porque el miembro presente ha de reemplazar al ausente en todas las funciones" (1994, p. 10). Después de la separación, las madres participantes del estudio asumieron la jefatura del hogar. En el caso de Silvana, ella expresó que su mamá es la encargada de darle los permisos. Su madre afirmó:
Yo siempre he llevado las riendas del hogar. (Participante 2).

Según Amaris:

[...] la principal característica de las mujeres jefe de hogar es su alta participación de la fuerza de trabajo, por ello adquieren obligaciones económicas con los otros miembros de la familia y al mismo tiempo se les otorga la autoridad suficiente para que se reconozcan como jefes del hogar. (2004, p. 26)

Cuando Luisa, la madre de Silvana, habló acerca de las normas en el hogar después de la separación, comentó.

yo le digo a ella que debe ser obediente en ciertas cosas, y le explico sus responsabilidades dentro del hogar. (Participante 2)

En este caso la comunicación permite tener claridad frente a las normas y a las funciones que asume cada individuo dentro del hogar.

En coherencia con lo anterior, actualmente los papeles se han transformado y ya no están definidos por el sexo. Para Gutiérrez (1999), por ejemplo, "las expectativas y las respuestas del rol son comunes a los dos sexos creando un tipo de autoridad en que ambos comparten normativamente la toma de decisiones y su ejecución" (p. 505). Por su parte, Sánchez (1984), afirma que "la separación no es argumento para que uno de los padres se desentienda de la educación de los hijos [...] ambos cónyuges, deben arreglarse para cumplir la misión educativa que corresponde a sus respectivos 'papeles' familiares" (p. 108). Sin embargo, tal como se evidencia en nuestro estudio, es recurrente que, después de la separación, el hombre tienda a ausentarse olvidando su papel como padre y delegando todas las funciones a la madre.

Cuando los niños participantes del estudio narraron sus experiencias frente a la autoridad y a los papeles después de la separación expresaron:

Yo le pido los permisos a mi mamá porque mi papá es el que le pide permiso a mi mamá. (Participante 1.1) 
Yo le pido permiso a mi mamá y por celular se lo pido también a mi papá; si mi mamá dice que sí, me pregunta ¿ya le pidió permiso también a su papá?, entonces yo cojo el celular y le pregunto por el WhatsApp. (Participante 4.1)

Mi mamá dice qué es lo que se debe hacer en la casa. (Participante 5.1)

Estos relatos hacen referencia a los papeles que asumen los miembros de la familia después de la separación y denotan la persona que asume la autoridad. Si bien es cierto que los relatos hablan de autoridad y no directamente de funciones, es necesario tener presente que, en el marco del estudio, la autoridad está vinculada a los roles, en tanto quien representa la figura de autoridad está ejerciendo un papel. Hay padres que evaden las responsabilidades en cuanto a los hijos y otros a pesar de la separación siguen cumpliendo su papel. A propósito, Gutiérrez menciona "como la mayor ausencia es del padre, la mujer colombiana cabeza económica de la familia está afrontando a raíz del cambio en la función que asume sola, una de las mayores dificultades de este tiempo" (1994, p. 10). La madre asume la función de padre y es la figura de autoridad ante sus hijos.

\section{El vínculo afectivo teje familias}

Cuando las madres quedan a cargo de la familia configuran redes de apoyo con otros miembros de la misma y establecen alianzas que les permiten adaptarse a los cambios que conlleva la separación. Como señala Rof-Carballo "el hombre establece su propia 'urdimbre afectiva' que será el entramado sobre el que se vayan tejiendo los más diversos aspectos de su maduración" (pp. 397 y 398). Cuando se da la ruptura entre los padres, estos buscan establecer vínculos con otros miembros de la familia, amigos o grupo social para sobrellevar las adversidades que supone este cambio; este es el caso de algunos participantes del estudio. Lorena en su relato manifestó:

La mamá de él es muy pendiente de Paulina, es el reemplazo de él. (Participante 6)
Paulina expresa:

Me gusta compartir mucho con una amiguita que vive por mi casa, porque a ella también se le separó la familia y me cuenta lo que le pasa, ella está muy triste y siempre llora. Yo le digo que esté tranquila porque a mí también me pasa lo mismo. (Participante 6.1).

En relación a la solidaridad y al interés de la participante por compartir con una amiga a quien le ha sucedido lo mismo, Cifuentes y Milicic Comentan que:

[...] las redes de apoyo son percibidas por los niños como recurso protector, se comprueba la eficacia de la presencia de vínculos con abuelos, hermanos mayores, compañeros de colegio y profesores. La relación entre pares se vuelve un referente que estimula a los niños a superar la crisis.

El altruismo entre los niños constituye un recurso maravilloso que surge de la vivencia empática de haber experimentado el dolor y sufrimiento. (2012, p. 479)

Esta situación similar entre Paulina y su amiga les permite identificarse y apoyarse mutuamente. A veces, cuando los niños comparten situaciones similares como lo es la separación de los padres, forman entre ellos redes de apoyo en las que comparten experiencias que los ayudan a estar tranquilos y a sentirse bien.

Según Riviere (2002), el vínculo es la manera particular en que un sujeto se conecta o relaciona con el otro o los otros. En cada caso y en cada momento, para Jerónimo, quien cumple las veces de padre es la expareja de la madre. María contó:

Raúl y yo empezamos cuando Jerónimo estaba muy chiquito y para él siempre ha sido la figura paterna. Raúl no tiene hijos y cuando empezamos nuestra relación, él dijo que a partir de ese momento él se hacía responsable del niño, el niño es mío. [...] Jero tiene muy claro que Raúl no es su papá biológico, él sabe quién es, aunque no lo conozca. Para Jero, Raúl es su papá. Él una vez me dijo, Raúl a mí me cuida, me da la comida, me lleva a la escuela, Raúl es mi 
papá; igual en la escuela y en muchas partes la figura paterna es la que siempre está ahí con nosotros. (Participante 1)

Y Jerónimo expresó que su familia la conforman:

mi mamá, mi papá (aunque no viva conmigo) mi abuela, mi tía, mis primos, mi otra tía y mi papá que es mi abuelo pero le gusta que yo le diga papá. (Participante 1.1)

El vínculo que se teje entre Raúl y Jerónimo a partir de la afectividad le permite a cada uno asumir un papel dentro del hogar $y$, aunque entre los dos no haya un vínculo sanguíneo, él lo considera su padre porque también suple las necesidades básicas y asume las responsabilidades y funciones de un padre.

En este sentido cabe esta afirmación: los roles sostienen el estatus familiar y estos dos dan el soporte para el cumplimiento de las funciones familiares. Por eso, las funciones no son lo mismo que roles o que estatus, pero se relacionan directamente con ellos. (Viveros, 2010, p. 395)

María afirma que cuando se dio el proceso de separación

Jerónimo empezó mal en el estudio, en lo académico. Jerónimo siempre ha sido una persona muy activa en todo, en absolutamente todo, súper buen deportista y habla en exceso, todos los profesores, en fútbol, en la escuela, en todas partes se me quejaban de eso, y me decían, iay es que Jerónimo no pone atención, hay que estarle repitiendo! y la verdad a mí eso me da rabia, porque a pesar de que él es tan activo hace las cosas bien, con la parte del habla no he sido capaz, creo que en este momento la tiene muy controlada. En este momento está muy juicioso, lo que pasa es que él empezó con alopecia, de hecho, todavía la tiene, en la parte de atrás de la cabeza. Los doctores me dicen que es alopecia infantil. Cuando lo llevé donde el dermatólogo me preguntó qué le había pasado, por qué suceso traumático había pasado Jerónimo y le echó la culpa a la separación, argumentando que fue una forma de transmitir eso. (Participante 1)

La separación de los padres influye en el desempeño académico del niño. La familia, en lugar de encontrar un apoyo en la escuela y un aliado que le permita enfrentar esta situación, se encuentra con un reto adicional que se debe atender.

Para Sierra (2008), el síntoma de la separación en los niños y adolescentes

Puede emerger de diferentes formas: fracaso escolar (expresado en dislexia, digrafía, discalculia, etc.), trastornos de la alimentación (anorexia, bulimia), consumo de sustancias psicoactivas, deserción escolar, trastornos emocionales (depresión, ansiedad, intentos de suicidio) y de comportamiento (hiperactividad, déficit de atención, impulsividad, objeción a la norma), entre otras. (pp. 160 y 161)

Luisa contó que el proceso de separación para ella fue muy complicado:

La situación económica estaba muy complicada porque yo me había quedado sin trabajo y un día mi papá me dijo: hija yo voy a tomar una casa usted si quiere se viene conmigo, con los muchachos y la niña pero Carlos no, y yo dije que sí, y pensé que esta era mi oportunidad para salir de esto y recuperar parte de mi vida, mi tranquilidad, [...] me fui a vivir con mi papá, conseguí un empleo, empecé a trabajar y ya fue mejorando la situación; con él viví un poco más de un año, mi papá me ha colaborado demasiado con la niña, porque en el trabajo tenía un horario muy extenso, sabía el horario de entrada mas no de salida, mi papá y mi mamá me colaboraban mucho con la niña, ella iba al apartamento, lo organizaba, llevaba a la niña a la guardería, nunca me he sentido sola. (Participante 2)

En la mayoría de los casos el apoyo de los abuelos juega un papel fundamental para sobrellevar este tipo de dificultades. Es por esto por lo que, a través del vínculo, se crea un entramado de relaciones que le permiten al sujeto relacionarse con otras personas y crear redes que brindan seguridad, confianza, protección y esperanza. 
El tiempo libre, un momento para compartir Una de las funciones que cumple la familia es la satisfacción emocional de sus miembros,

Todo hombre, por el hecho de serlo, tiene una serie de necesidades que pueden ser satisfechas en el ambiente familiar, a través de las relaciones entre los padres o de éstos con sus hijos. Son, por ejemplo, la seguridad emocional, sentimiento de dependencia, de pertenencia a un grupo, admiración mutua, deseo de agradar, sentirse querido o necesario para los otros. (Sánchez, 1984, p. 18)

Para Gutiérrez (1994), "el ambiente psicoafectivo de la familia está vinculado a las demostraciones de afecto y a los momentos de tiempo libre en los que comparten los miembros" (p.10), cuando los padres se separan estos tiempos de esparcimiento, en que los miembros de la familia pueden disfrutar y compartir sin pensar en estudio, trabajo o deberes del hogar, varían. Sierra menciona que la separación de los padres "implica para el niño el derrumbamiento de su mundo, de un nido protector, cálido y confortable algunas veces, y muy posiblemente idealizado por el amor recibido en las primeras épocas de su vida" (2008, p. 77).

Este es el caso de Silvana, quien antes de la separación pasaba la mayor parte del tiempo con su padre en casa, debido a que la madre era la proveedora económica del hogar y debía salir a trabajar; después de la separación Silvana perdió contacto con su padre. Por lo anterior, en sus discursos expresó que anhela verlo, compartir tiempo con él, y afirma que la persona con quien le gusta pasar la mayor parte del tiempo, a pesar de no hacerlo, es con su padre, esto para poder acercarlo a su vida. Al respecto manifiesta:

Me gusta estar un poquito más con mi papá porque yo casi no lo veo. (Participante 2.1)

Ante esta situación, a Silvana le ha tocado enfrentar el desplome de su vida afectiva, pues antes compartía todo el tiempo con su padre y ahora él está ausente.

María, la madre de Jerónimo, expuso que la actividad más importante que realizaban en familia antes de separarse era que siempre veían televisión o películas juntos (Participante 1). Pero, después de la separación ya no realizan este tipo de actividades y expresó que ella cree que su hijo cambió la forma de ver y de pensar la familia porque:

a partir de ese momento se centró más en mí, los dos nos volvimos prácticamente uno. Nos refugiamos el uno con el otro. (Participante 1)

A causa de la separación de los padres, el hijo y la madre reafirman los lazos afectivos que antes no se veían tan marcados. Estos lazos se establecen por la necesidad de ambos de sentirse queridos y de re-organizar su grupo familiar. En uno de los talleres realizados con los niños participantes, Jerónimo al explicar su dibujo expresó:

Me dibujé a mí, a mi papá con otra novia y a mi mamá trabajando muy triste, dibujé un corazón roto porque los dos se querían mucho, aunque mi papá tenía otra novia, quería a mi mamá. (Participante 1.1)

Bowlby (1990, citado en Gallego, 2012) afirma que "el intercambio afectivo, es una de las interacciones más importantes en la vida del ser humano, debido a que el sentirse amado, respetado y reconocido potencia la satisfacción personal y el desarrollo humano al interior del grupo familiar" (p. 335). Al respecto, Paulina comentó:

A veces cuando mi mamá no me deja salir a jugar yo me enojo con ella, y ella al momentico me abraza y ya. (Participante 6.1)

Esto evidencia que las demostraciones de afecto de la madre calman las emociones de tristeza y enojo de los hijos y que, cuando los niños comparten tiempo con sus padres, se sienten queridos, amados. Por este motivo el tiempo libre se relaciona con el afecto.

\section{La comunicación después de la separación}

En este apartado se entiende la comunicación como el medio en que las personas del grupo familiar expresan los pensamientos, emociones y sentires a través de acciones o lenguaje verbal y no verbal. 
Esta consideración surge a partir de la triangulación de los testimonios dados por los participantes del estudio durante las entrevistas.

Después de la separación, la comunicación entre los miembros de la familia, en especial la de los padres, se modifica. Los niños dijeron que después de la separación si los padres hablan lo hacen es discutiendo. En algunos casos la comunicación se pierde y los niños se ven en la necesidad de expresarle al padre ausente las necesidades que se presentan en el hogar. Cifuentes y Milicic afirman que:

Un elemento que afecta la valoración de la experiencia, tiene que ver con el registro de conflictos y peleas entre los padres, aun después de la separación, incluso cuando han trascurrido algún tiempo de este episodio. Estas dinámicas de perpetuación del conflicto dificultan los procesos de asimilación y adaptación de los hijos al nuevo contexto familiar. (2012, p. 479)

Algunos niños manifestaron sobre la comunicación entre los padres después de la separación lo siguiente:

No les gusta hablarse, aunque no se pelean, prefieren no hablarse. (Participante 1.1)

Mis papás a veces se hablan, pero terminan peleando y se cuelgan. Cuando mi papá me habla, me pregunta cómo estoy, qué necesito, pero yo no sé qué pedirle, mi mamá me dice que le pida muchas cosas, que de verdad necesito, pero yo no sé qué pedirle. (Participante 3.1)

Ahora mis papás se hablan, pero cuando yo tenía 5 o 6 años, sí mi mamá llamaba a mi papá para pedirle algo para mí, hablaban bien un ratico y después se ponían a pelear. (Participante 2.1)

En este último caso, la participante 2 reafirma estas dificultades al expresar:

Yo me comunico con él de vez en cuando, lo menos posible, solo para cosas que sí toca hablar con él, yo por lo general me comunico es con la mamá, no me gusta conversar con él porque siempre que hablamos terminamos en discusiones. (Participante 2)

En algunos casos, las dificultades entre los padres se transfieren a los hijos. Cifuentes y Milicic exponen que:

Para los niños es fundamental recibir un mensaje honesto y esperanzador de parte de los adultos que expliciten temas como las visitas, el lugar donde vivirá el padre luego de la separación y si podrán reunirse en ese sitio con él. Los niños enfrentan la reestructuración de su ambiente familiar y, en consecuencia, les resulta profundamente aliviador que se les garantice la continuidad del vínculo con el padre, además del compromiso de término de conflictos en el hogar. Esto constituye el elemento diferenciador que permite alentar las fuerzas de los niños para hacer frente a la separación. (2012, p. 479)

Así, la buena comunicación entre los miembros de la familia permite a los niños afrontar la separación de sus padres con mayor claridad y tranquilidad.

\section{Conclusiones}

Después de revisar los resultados y realizar el análisis (para identificar el imaginario de familia que configuran los niños hijos de padres separados) se concluye que una vez ocurrida la ruptura el imaginario de familia se transforma. Los niños desean tener a su familia unida, pese a las dificultades por las que hayan atravesado durante el proceso. Esto hace que el imaginario de familia antes de la separación esté ligado a la felicidad.

Por otro lado, la dinámica familiar influye en el imaginario de familia que configuran los niños. Cuando la familia se diluye los papeles, la autoridad, el afecto, la comunicación y el tiempo libre se transforman, pues cambian las actividades y formas de hacer las cosas que hasta entonces se habían establecido en el hogar. Estos cambios relacionan el imaginario de familia con la tristeza.

La comunicación entre los padres se deteriora y en algunos casos se pierde. En medio quedan los niños quienes deben lidiar con esta situación y 
ser intermediarios. En cuanto al afecto y el tiempo libre es recurrente que los niños deseen compartir tiempo con sus padres y que este resulte ser una demostración de afecto entre los miembros.

A través del vínculo se establecen relaciones filiales y redes de apoyo que permiten a los sujetos afrontar las dificultades, sentirse reconocidos, apoyados, queridos y pertenecer a un grupo.

Por último, cabe resaltar que la relación dialéctica entre familia y escuela es indispensable para la educación de los niños. Así como la escuela solicita el apoyo de la familia, la familia espera encontrar el soporte de la institución educativa para sobrellevar de la mejor manera las dificultades que se presentan durante y después del proceso de separación para que el impacto de esta, en la vida de los niños, no sea tan fuerte.

\section{Referencias}

Amaris, M. (2004). Roles parentales y el trabajo fuera del hogar. Psicología desde el Caribe, 13.

Bonilla Castro, E. y Rodríguez, P. (1995). Más allá del dilema de los métodos. Cede, Facultad de Economía Universidad de los Andes.

Bruner, J. (1988). Realidad mental, mundos posibles. Gedisa.

Cifuentes, O. y Milicic, N. (2012). Crisis en la infancia: ¿qué piensan, sienten y dicen los niños sobre la separación de sus padres? Universitas Psychologica, 11(2), 469-480. http://www.redalyc.org/articulo. oa? id=64723241010

Corman, L. (1967). Test del dibujo de la familia. Editorial Kapelusz S. A.

Correa, L. V., Vargas, E. D. y Gallego, A. M. (octubre de 2016). El niño y su imaginario de familia. Simposio de Investigación Ustamed. Medellín, Colombia.

Dinero (20 de abril de 2017). Divorcios en Colombia aumentaron un 39 \% desde 2014. https://www.dinero.com/pais/articulo/matrimonios-y-divorcios-en-colombia-a-2017/244352

Domínguez, X. M. (2007). Antropología de la familia: persona, matrimonio y familia. Biblioteca de Autores Cristianos.
Escobar, J. C. (2000). Lo imaginario. Entre las Ciencias Sociales y la Historia. Fondo Editorial Universidad Eafit.

Gadamer, G. H. (2007). Verdad y método. Salamanca.

Gallego, A. M. (2012). Recuperación crítica de los conceptos de familia, dinámica familiar y sus características. Revista Virtual Universidad Católica del Norte, 35, 326-345.

García, B. E., González, S. P., Quiroz, A. y Velásquez, A. M. (2002). Técnicas interactivas para la investigación social cualitativa. Funlam.

Gutiérrez de Pineda, V. (1994). Modernización, tendencias poblacionales y transformación de las funciones de la familia. Segundo Congreso de Trabajo Social "Funciones y responsabilidades de la familia en un mundo en evolución". Organizado por la Asociación Sindical de Trabajadores Sociales, (19, 20 y 21 de octubre)

Gutiérrez de Pineda, V. (1999). Estructura, función y cambio de la familia en Colombia. Editorial Universidad de Antioquia.

Lacan, J. (1977). La familia. Ediciones Homo Sapiens.

Muñoz-Ortega, M. L., Gómez-Alaya, P. A. y Santamaría-Ogliastri, C. M. (2009). Pensamientos y sentimientos reportados por los niños ante la separación de sus padres. Universitas Psychologica, 7(2), 356. https://revistas.javeriana.edu.co/index.php/ revPsycho/article/view/347

Páez, G. (1984). Sociología de la familia. Universidad Santo Tomás.

Porlán, R. y Martín, J. (2000). El diario de un profesor: un recurso para la investigación en el aula. Díada.

Riviere, P. (2002). Teoría del vínculo. Ediciones Nueva Visión.

Rof-Carballo, J. (1976). La familia, diálogo recuperable. Karpós.

Sánchez, E. (1984). Familias rotas y educación de los hijos. Narcea S. A.

Sierra, G. L. (2008). Los hijos del divorcio. Editorial Corporación Ser Especial.

Turrent, J. y Villaseñor, M. C. (2009). Los niños y los otros. Dos estudios de caso a cerca del 
imaginario y la diferencia. Zona próxima, Revista del Instituto de Estudios en Educación Universidad del Norte, 10, 80-103.

Uribe, P. I. (2012). Familias, organización y dinámicas. En Aprender a ser familia. Universidad de la Salle.
Viveros, E. F. (2010). Roles, patriarcado y dinámica interna familiar: reflexiones útiles para Latinoamérica. Revista Virtual Universidad Católica del Norte, 31, 388-406.

https://www.redalyc.org/articulo. oa? id=1942/194214587017

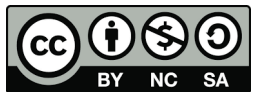

Esta obra está bajo licencia Creative Commons Atribución-NoComercial-Compartirlgual 4.0 Internacional 